\title{
Pendampingan Penulisan Artikel Ilmiah bagi Komunitas Guru Sekolah Dasar Melalui Service Learning Approach di Kecamatan Sukun Kota Malang
}

\author{
Ifit Novita Sari, Dwi Fita Heriyawati \\ Universitas Islam Malang \\ E-mail: inovsari@unisma.ac.id
}

\section{Article History:}

Received: Sept $13^{\text {th }} 2019$

Revised: Aug $18^{\text {th }} 2020$

Accepted: Nov 30th 2020

Keywords: scientific articles, teachers, service learning approach.

\begin{abstract}
One of the rarely trained skills of the teachers in writing scientific papers. The reason is that the teachers are less trained to write a scientific article. Currently, scientific articles are one of the mandatory requirements for promotion for teachers. This community service activity is intended to assist teachers in writing scientific articles based on the results of classroom action research (PTK) that has been carried out. The method was conducted through workshops, discussions, questions and answers, face-to-face guidance services, and e-mail. The results indicated a paradigm shift in writing scientific articles. Initially, the teachers experienced difficulties, but after the training, they felt easy because they already knew how to put the ideas of the CAR (PTK) results in article writing. The results indicate that with further instruction and guidance, the teachers' capacity improves and the drafts were good with some improvement The articles will then published in accredited journals for the teachers' promotion.
\end{abstract}

\section{Pendahuluan}

Guru sebagai unsur utama dalam proses belajar mengajar di sekolah harus memiliki kualifikasi dan profesionalisme dalam mendidik, mengajar, membimbing, mengarahkan, melatih, menilai, dan mengevaluasi. Dengan kualifikasi tersebut akan berdampak terhadap kualitas pembelajaran sebagai barometer tercapainya tujuan pendidikan nasional, yaitu: mengembangkan potensi peserta didik agar menjadi manusia yang beriman, dan bertakwa kepada Tuhan Yang Maha Esa, berakhlak mulia, sehat, berilmu, cakap, kreatif, mandiri, dan menjadi warga negara yang demokratis serta bertanggung jawab. Guru yang profesional akan memiliki dampak positif terhadap peningkatan kualitas pendidikan, demikian sebaliknya jika guru tidak profesional maka kualitas pendidikan tidak akan dapat meningkat dengan baik. ${ }^{1}$

1 Ifit Novita Sari, “Kepemimpinan Moral-Spiritual Guru Dalam Pembentukan Karakter Peserta Didik (Studi Multikasus Di Sekolah Dasar Plus Al Kautsar, Sekalah Dasar Negeri Kauman I, Dan Sekolah 
Pentingnya peranan guru dalam memajukan pendidikan nasional dan menyiapkan sumber daya manusia yang berkualitas, guru yang berkualitas di masa sekarang dan di masa yang akan datang mutlak diperlukan. Untuk itu, pemerintah melalui Menteri Negara Pendayaan Aparatur Negara mengeluarkan Permenegpan Nomor 16 Tahun 2009 tentang Jabatan Angka Fungsional Guru dan Angka Kreditnya. ${ }^{2}$

Unsur dan sub unsur kegiatan guru yang dinilai angka kreditnya meliputi pendidikan, pembelajaran/pembimbingan, pengembangan keprofesian berkelanjutan, dan penunjang. Pengembangan keprofesian berkelanjutan meliputi sub unsur pengembangan diri, publikasi ilmiah, dan karya inovatif. Senada dengan Permenegpan Nomor 16 Tahun 2009 maka Permendiknas nomor 35 tahun 20103, juga memuat tentang Petunjuk Teknis Pelaksanaan Jabatan Fungsional Guru dan Angka Kreditnya menuntut guru menghasilkan karya ilmiah untuk dipublikasikan. Kebijakan ini secara ketat mengatur perhitungan angka kredit jabatan fungsional guru untuk urusan kenaikan pangkat dan golongan. Regulasi yang berlaku efektif 1 Januari 2013 ini pada pasal 17 menyatakan bahwa, kenaikan pengkat III/b ke III/c, III/c ke III/d, III/d ke IV/a, IV/a ke IV/b, IV/b ke IV/c, IV/c ke IV/d dan IV/d ke IV/e wajib melaksanakan kegiatan pengembangan diri (pelatihan dan kegiatan kolektif guru) dan publikasi ilmiah/karya inovatif (karya tulis ilmiah, membuat alat peraga, alat pelajaran, karya teknologi/seni) masing-masing akan mendapatkan besaran angka kredit. ${ }^{4}$

Kendala utama dalam pengumpulan angka kredit tersebut adalah unsur pengembangan profesi yang mengharuskan guru membuat karya tulis ilmiah dan atau karya inovatif. Para guru kesulitan untuk memenuhi unsur tersebut karena sebelumnya tidak terlatih atau belum pernah membuat karya tulis ilmiah serta karya inovatif. ${ }^{5}$ Kesulitan guru dalam menulis karya ilmiah datang dari pribadi guru itu sendiri, diantaranya: (1) budaya membaca. Membaca disini tidak dimaksudkan pada sekedar membaca buku pelajaran melainkan membaca buku buku sumber lain yang

Dasar Katolik Santa Maria II Di Kota Malang)" (Universitas Negeri Malang, 2017), http://repository.um.ac.id/64010/.

${ }^{2}$ Supardi Supardi, "Implementasi PERMENEGPAN No. 16 Tahun 2009 Tetang Jabatan Fungsional Guru Dan Angka Kreditnya Untuk Peningkatan Profesionalisme Guru," in Penilaian Kinerja Untuk Peningkatan Profesionalisme Guru Berkelanjutan, 2012; Sari, "Kepemimpinan Moral-Spiritual Guru Dalam Pembentukan Karakter Peserta Didik (Studi Multikasus Di Sekolah Dasar Plus Al Kautsar, Sekalah Dasar Negeri Kauman I, Dan Sekolah Dasar Katolik Santa Maria II Di Kota Malang)."

3 Depdiknas, "Permendiknas No. 35 Tahun 2010 Tentang Petunjuk Teknis Pelaksanaan Jabatan Fungsional Guru Dan Angka Kreditnya” (Jakarta, Indonesia: Departemen Pendidikan Nasional, 2010).

${ }^{4}$ Ibid.

${ }^{5}$ Meirizal Usra, H Hartati, and D Destriani, "Pelatihan Penulisan Artikel Ilmiah Bagi Guru Sekolah Menengah Atas" (Seminar Nasional Pendidikan 2018, 2018); Rangga Sa'adillah S.A.P. et al., "Dampak Pendekatan Saintifik Terhadap Sikap Spiritual Siswa Dalam Pembelajaran PAI Di SMA Di Sidoarjo," Jurnal Pendidikan Agama Islam (Journal of Islamic Education Studies) 7, no. 2 (2019): 143-165; Abdul Rasyid Tolangara and Rohima Wahyu Ningrum, "Pendampingan Komunitas Sekolah Melalui Kegiatan Vertical Garden Untuk Mewujudkan Sekolah Dasar Berbasis Lingkungan Di SDN 34 Kota Ternate Maluku Utara," Engagement: Jurnal Pengabdian Kepada Masyarakat 2, no. 1 (2018): 62-70, http://engagement.fkdp.or.id/index.php/engagement/article/view/24. 
berhubungan dengan pendidikan, metode-metode penelitian, teknik penelitian, penilaian, dan lain lain. Aktivitas membaca menjadi faktor urgent dalam mendukung seorang melakukan penelitian dan menulis sebagai syarat kenaikan pangkat dan golongan, (2) semangat guru. Rutinitas harian di kelas mestinya memacu guru untuk terus merefleksikan setiap proses pembelajaran di kelas. Motivasi yang kuat dalam diri setiap guru mendukung aktivitas menulis. ${ }^{6}$

Pada saat berlangsungnya kegiatan belajar mengajar, guru juga melakukan kegiatan penelitian tindakan kelas (PTK) yang dimaksudkan untuk memperbaiki dan meningkatkan layanan profesional guru dalam proses pembelajaran. Beberapa siklus bisa dilakukan sampai apa yang diharapkan tercapai. Hasil PTK akan menjadi rujukan bagi guru dalam pengembangan profesinya sehingga guru makin produktif dan percaya diri secara keilmuan. Guru lebih berani mengambil inisiatif untuk memberikan manfaat perbaikan dan kepercayaan dirinya tumbuh karena guru tersebut sering mengembangkan pengetahuannya sendiri dengan pengalaman praktis sehari-hari di kelas pada saat pembelajaran berlangsung. Hasil PTK merupakan pengetahuan baru bagi guru dan perlu dipublikasikan kepada khalayak agar dapat menjadi rujukan bagi guru lainnya dalam pengembangan profesi guru. Hal ini yang belum dilakukan oleh guru karena keterbatasan keterampilan dalam menuangkan hasil PTK ke dalam sebuah artikel ilmiah.

Berdasarkan uraian diatas, bahwa guru sudah memiliki kemampuan dan ketrampilan dalam Penelitian Tindakan Kelas, namun masih belum terbiasa menyusun dalam sebuah artikel sesuai dengan standar jurnal nasional, karena mereka lebih banyak bertumpu dalam proses belajar mengajar di kelas. Oleh karena itu, maka sebenarnya guru sudah memiliki modal yang baik untuk dikembangkan kemampuannya dalam skill menulis artikel ilmiah dengan menuliskan kembali apa yang sudah dilakukan dalam PTK. Hasil PTK dimanfaatkan untuk perbaikan model pembelajaran di kelas dan layak dipublikasikan dalam bentuk artikel ilmiah yang dimuat di jurnal ilmiah.

Dari latar belakang di atas, kondisi secara umum juga tidak jauh berbeda kesulitan yang dialami oleh para Guru SD sederajat di Kecamatan Sukun Kota Malang yang mencapai 1.043 Guru dengan rincian sebagai berikut:

Tabel 1. Jumlah sekolah dan Guru Tingkat SD sederajat di Kecamatan Sukun7

\begin{tabular}{|c|c|c|c|c|c|}
\hline \multirow{2}{*}{ No } & \multirow{2}{*}{ Jenis Sekolah } & \multicolumn{2}{|c|}{ Jumlah Sekolah } & \multicolumn{2}{|c|}{ Jumlah Guru } \\
\hline & & Negeri & Swasta & Negeri & Swasta \\
\hline 1 & Sekolah Dasar & 42 & 19 & 603 & 250 \\
\hline 2 & Madrasah Ibtidaiyah & 1 & 11 & 46 & 144 \\
\hline
\end{tabular}

${ }^{6}$ Eny Nur Aisyah and Putri Mahanani, "Pelatihan Menulisan Artikel Ilmiah Bagi Guru Sekolah Dasar Dan Taman Kanak-Kanak Kecamatan Tajinan Kabupaten Malang," Abdimas Pedagogi:Jurnal Ilmiah $\begin{array}{llllll}\text { Pengabdian kepada } & \text { Masyarakat } 1, & \text { no. } & 1 & \text { (2017): }\end{array}$ http://journal2.um.ac.id/index.php/pedagogi/article/view/1947. 2020). 
Untuk meminimalisir kendala yang dialami oleh para guru, maka Tim melakukan pendampingan untuk Guru Sekolah Dasar di lingkungan gugus IX Kecamatan Sukun, Kota Malang yang akan mengajukan kenaikan pangkat untuk membuat membuat karya ilmiah sekaligus pendampingan publikasi di jurnal ilmiah nasional.

Kegiatan pengabdian bertujuan untuk menambah wawasan baru bagi guru tentang seluk beluk penulisan artikel ilmiah dan menepis anggapan betapa sulitnya menulis sebuah artikel ilmiah, serta artikel ilmiah yang dihasilkan memiliki stdanr kualitas yang baik untuk dapat dipublikasikan pada jurnal-jurnal ilmiah nasional.

\section{Metode}

Metode yang digunakan dalam kegiatan pengabdian masyarakat ini menggunakan pendekatan service learning. Hal ini dimaksudkan untuk pembelajaran dalam mengatasi masalah dan pemenuhan kebutuhan praktis yang dibutuhkan oleh komunitas dampingan dengan untuk menemukan solusi dari masalah yang dihadapi oleh subyek yang dilakukan melalui tiga tahap, yakni tahap persiapan, tahap melayani, dan tahap refleksi. ${ }^{8}$ Subyek kegiatan pengabdian adalah kepala sekolah dan guru SD di lingkungan gugus IX Kecamatan Sukun, Kota Malang, sebanyak 25 orang terdiri dari 7 kepala sekolah dan 18 guru yang akan mengajukan kenaikan pangkat.

Tahap persiapan, dilakukan dengan koordinasi dan FGD dengan ketua gugus IX Guru SD di kecamatan Sukun, Kota Malang serta mengidenfitikasi kemampuan awal guru tentang pengetahuan penulisan artikel ilmiah.

Tahap kedua, yakni tahap melayani dilakukan dengan workshop dengan para Guru SD terkait materi dan informasi tentang bagaimana menulis artikel yang baik dan

8 Irene Nusanti, "Strategi Service Learning Sebuah Kajian Untuk Mengembangkan Kegiatan Pembelajaran," Jurnal Pendidikan dan Kebudayaan 20, no. 2 (2014): 251-260, http://up.openjournaltheme.com/jurnaldikbud/ojs-3.1.2-4/index.php/jpnk/article/view/142.; $\quad$ Muh Barid Nizarudin Wajdi et al., "Pendampingan Redesign Pembelajaran Masa Pandemi Covid-19 Bagi Tenaga Pendidik Di Lembaga Pendidikan Berbasis Pesantren Di Jawa Timur," Engagement: Jurnal Pengabdian Kepada Masyarakat 4, no. 1 (2020): 266-277, http://engagement.fkdp.or.id/index.php/engagement/article/view/193; Ayi Olim, "Mencari Metode Pendidikan Karakter Untuk PAUD: Belajar Berbasis Layanan (Service Learning)," in Proceedings of the 4th International Conference on Teacher Education (Bandung, 2010), 146-161, http://file.upi.edu/Direktori/PROCEEDING/UPI-

UPSI/2010/Book_1/MENCARI_METODE_PENDIDIKAN_KARAKTER_UNTUK_PAUD_BELAJAR_BERBASIS_L AYANAN_\%28SERVICE_LEARNING\%29.pdf; Leora S Waldner, Murray C Widener, and Sue Y McGorry, "EService Learning: The Evolution of Service-Learning to Engage a Growing Online Student Population," Journal of Higher Education Outreach and Engagement 16, no. 2 (2012): 123-150, https://files.eric.ed.gov/fulltext/EJ975813.pdf; Amang Fathurrohman et al., "Peningkatan Kapasitas Fotografer Pemula Melalui Sekolah Fotografi Online (SeFO) Tingkat Jawa Timur Untuk Mewujudkan Fotografer Mahir Dengan Handphone Di Masa Pandemik Covid-19," SOEROPATI 2, no. 2 (2020): 1-8, https://jurnal.yudharta.ac.id/v2/index.php/soeropati/article/view/2064. 
benar sesuai dengan kaidah penulisan artikel ilmiah. Kegiatan ini dimaksudkan untuk memberi informasi kepada para guru yang belum mengetahui teori bagaimana menulis artikel ilmiah, dilanjutkan dengan pengenalan beberapa contoh artikel ilmiah yang baik dan diterima untuk dimuat di jurnal yang bereputasi. Hal ini dimaksudkan supaya guruguru dapat meningkatkan kemampuan menulisnya, sehingga guru memiliki pengetahuan tentang berbagai macam model penulisan artikel ilmiah.

Dalam tahap layanan ini juga dilakukan waktu tanya jawab seputar masalah dan kendala guru dalam menulis artikel ilmiah sekaligus pendampingan klinis penulisan artikel ilmiah guru yang diambil dari hasil PTK sehingga para guru memiliki kemampuan minimal membuat draf artikel ilmiah sesuai standar jurnal nasional.

Tahap ketiga, yakni tahap refleksi, yakni melakukan evaluasi hasil pendampingan terhadap para guru dalam menyusun karya ilmiah sesuai standar jurnal ilmiah nasional.

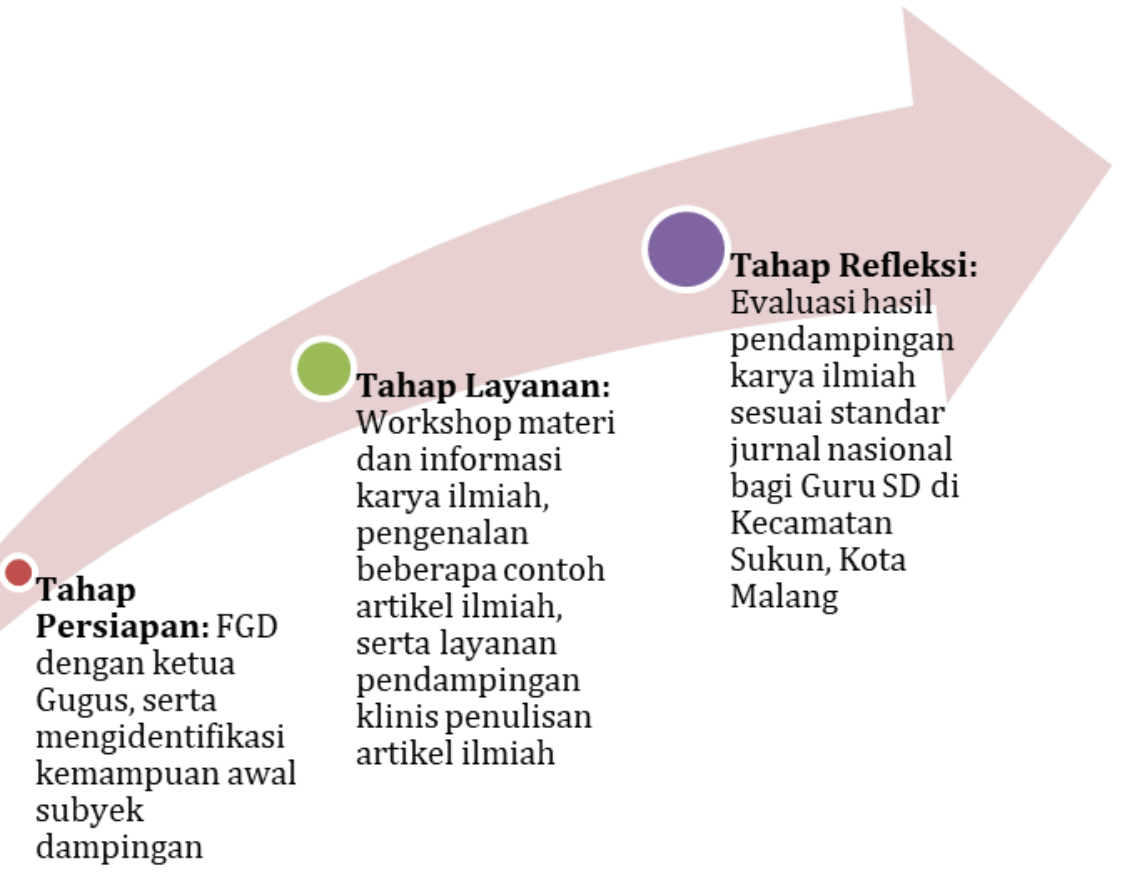

Gambar 1. Tahapan Kegiatan Pengabdian

\section{Hasil}

\section{Persiapan Peningkatan Kapasitas Guru SD dalam Menulis Karya Ilmiah}

Persiapan pendampingan ini dilakukan melalui Focus Grup Discussion yang dimotori oleh Ketua Gugus IX, sekaligus sebagai Kepala sekolah SDN Tanjungrejo 3, Kecamatan Sukun, Kota Malang. Hasil FGD menunjukkan bahwa para Guru SD yang akan naik kepangkatan memiliki kesulitan dalam artikel karya ilmiah di jurnal nasuonal.

Para Guru SD pada dasarnya sudah memiliki kemampuan dalam menulis karya 
ilmiah berupa laporan Penelitian Tindakan Kelas yang sudah sering mereka lakukan sebagai bagian dari evaluasi hasil pembelajaran. Namun, kemampuan untuk menulis artikel dan dipublikasikan dalam jurnal ilmiah nasional masih belum pernah mereka lakukan, kalaupun ada, sangat kecil sekali. Karena karya tulis ilmiah yang dipublikasikan bukan menjadi kewajiban yang harus mereka lakukan, kecuali pada saat akan melakukan kenaikan pangkat pada golongan tertentu. Maka tidak heran apabila para guru mengalami kesulitan untuk menyusun karya ilmiah sesuai standar jurnal nasional.

Berangkat dari permasalahan sekaligus potensi yang dimiliki oleh guru, maka Pengurus Gugus IX kecamatan Sukun berinisatif untuk mengkoordinasi semua guru yang akan melakukan kenaikan pangkat untuk dilakukan pendampingan secara intensif oleh Tim pendamping dalam menyusun artikel ilmiah yang dipublikasikan di jurnal nasional agar mereka mampu memenuhi persyaratan yang dibutuhkan dalam kenaikan pangkat jabatan. Hasil koordinasi dengan para guru SD di Gugus IX Kecamatan Sukun terdapat 25 Guru SD yang akan mengajukan kenaikan pangkat sangat respon untuk mengikuti pendampingan secara intensif dalam peningkatan kapasitas Guru SD dalam karya tulis ilmiah di jurnal ilmiah nasional.

\section{Layanan bagi Guru SD dalam Pendampingan Peningkatan Kapasitas Kemampuan Menulis Karya Ilmiah di Jurnal Nasional}

Agar mendapatkan pemahaman bersama terkait standar karya ilmiah di jurnal nasional, maka Tim pendamping memulai layanan ini dengan menyelenggarakan workshop penulisan artikel ilmiah. Tim memberikan paparan terkait penulisan karya ilmiah yang layak dipublikasikan di jurnal ilmiah nasional, dimulai dengan menjelaskan tentang makalah/artikel karya tulis ilmiah di jurnal ilmiah, jenis makalah / artikel dalam jurnal ilmiah, tata cara penulisan artikel ilmiah pada jurnal ilmiah, serta contohcontoh karya ilmiah yang sudah terpublikasi pada jurnal nasional.

Hasil yang diperoleh melalui kegiatan workshop ini adalah: (1) Kepala Sekolah dan Guru SD memperoleh pengetahuan dan wawasan baru tentang penulisan artikel ilmiah, (2) kepala sekolah dan guru mampu menerapkan tata cara atau aturan dalam menulis artikel ilmiah, (3) kepala sekolah dan guru mampu menuangkan ide dari hasil PTK ke dalam artikel ilmiah sebagai kajian baru dalam pembelajaran, (4) kepala sekolah dan guru memiliki keterampilan menuliskan artikel ilmiah berdasarkan hasil penelitian maupun kajian pustaka.

Tahap selanjutnya adalah melakukan pendampingan untuk mempraktekand ari materi yang telah disampaikan melalui workshop dengan membuat artikel ilmiah. Hasil assessment awal, sebanyak $50 \%$ peserta sudah memahami pengetahuan dan keterampilan teknik menulis artikel ilmiah. Sedangkan sisanya (50\%) masih perlu bimbingan secara intensif agar dapat memahami dan mempraktekkan menulis karya ilmiah sesuai dengan standar jurnal ilmiah nasional. 
Setelah melakukan tahap praktek penyusunan artikel ilmiah, para guru semakin terasah kemampuan mereka dalam penulisan artikel ilmiah. Perubahan pola pikir bahwa membuat artikel ilmiah sulit sudah mulai hilang. Hal ini terlihat dari muncul berbagai ide karya ilmiah yang dikembangkan dari hasil PTK yang sudah dilakukan oleh guru. Para guru juga telah mampu membuat draf artikel ilmiah, walaupun masih memerlukan bimbingan yang lebih intensif lagi.

Untuk memastikan seluruh Guru SD mempunyai kemampuan dalam menulis karya ilmiah sesuai dengan standar yang telah ditetapkan dalam jurnal nasional, tim pendamping juga memberikan panduan langkah-langkah penulisan artikel ilmiah yang terangkum dalam buku modul. Selain itu, draft artikel yang telah disusun terus dilakukan pendampingan intensif melalui media email, sehingga semua draft artikel yang telah disusun oleh para Guru SD dapat diselesaikan dalam bentuk artikel yang memiliki kualitas baik dan layak publish di jurnal nasional.

\section{Refleksi; Dari Ide menjadi Naskah Karya Ilmiah Layak Publish di Jurnal Ilmiah Nasional}

Hasil refleksi dari pendampingan yang diberikan secara intensif kepada para Guru SD tentang penulisan artikel ilmiah layak publish di jurnal nasional, terdapat perubahan baik pada pengetahuan maupun ketrampilan, dengan rincian sebagai tersaji dalam Tabel 2.

Tabel 2. Refleksi Hasil Pendampingan Karya Tulis Ilmiah bagi Guru SD

\begin{tabular}{|c|c|c|c|}
\hline No & Sebelum Pendampingan & Selama Pendampingan & Setelah Pendampingan \\
\hline 1 & $\begin{array}{l}\text { Sama sekali tidak memiliki } \\
\text { pengetahuan tentang } \\
\text { menulis artikel ilmiah }\end{array}$ & $\begin{array}{l}\text { Diberi } \\
\text { wawasan/pengetahuan } \\
\text { tentang menulis artikel } \\
\text { ilmiah }\end{array}$ & $\begin{array}{l}90 \% \text { peserta memahami } \\
\text { pengetahuan tentang } \\
\text { menulis artikel ilmiah }\end{array}$ \\
\hline 2 & $\begin{array}{l}\text { Tidak memiliki pengetahuan } \\
\text { tentang perbedaan artikel } \\
\text { ilmiah berbasis penelitian } \\
\text { dan nonpenelitian }\end{array}$ & $\begin{array}{l}\text { Diberi pengetahuan } \\
\text { tentang perbedaan artikel } \\
\text { ilmiah berbasis penelitian } \\
\text { dan nonpenelitian }\end{array}$ & $\begin{array}{l}90 \% \text { peserta memahami } \\
\text { pengetahuan tentang } \\
\text { perbedaan artikel ilmiah } \\
\text { berbasis penelitian dan } \\
\text { nonpenelitian }\end{array}$ \\
\hline 3 & $\begin{array}{l}\text { Tidak memiliki pengetahuan } \\
\text { dan keterampilan tentang } \\
\text { tata cara penulisan artikel } \\
\text { ilmiah }\end{array}$ & $\begin{array}{l}\text { Diberi pengetahuan dan } \\
\text { keterampilan tentang tata } \\
\text { cara penulisan artikel } \\
\text { ilmiah }\end{array}$ & $\begin{array}{l}90 \% \text { peserta memahami } \\
\text { pengetahuan dan } \\
\text { keterampilan tentang tata } \\
\text { cara penulisan artikel } \\
\text { ilmiah }\end{array}$ \\
\hline 4 & $\begin{array}{l}\text { Tidak memiliki keterampilan } \\
\text { praktis tentang penulisan } \\
\text { artikel ilmiah yang berasal } \\
\text { dari hasil PTK }\end{array}$ & $\begin{array}{l}\text { Dilatih keterampilan } \\
\text { praktis tentang penulisan } \\
\text { artikel ilmiah yang } \\
\text { berasal dari hasil PTK }\end{array}$ & $\begin{array}{l}50 \% \text { peserta memiliki } \\
\text { keterampilan praktis } \\
\text { tentang penulisan artikel } \\
\text { ilmiah yang berasal dari } \\
\text { hasil PTK }\end{array}$ \\
\hline
\end{tabular}


Para Guru SD juga mengalami perubahan pola pikir dari semula merasa kesulitan dalam penulisan artikel ilmiah menjadi mengerti bagaimana caranya menuangkan hasil PTK ke dalam sebuah artikel ilmiah. Sebagian dari Guru SD sudah memiliki keterampilan praktis tentang penulisan artikel ilmiah yang berasal dari hasil PTK karena mereka bersikap terbuka dan mau menerima tantangan untuk dapat menulis artikel ilmah. Sedangkan 50\% lainnya terkendala dengan faktor usia dan keterampilan menggunakan perangkat elektronik penunjang untuk menulis artikel ilmiah, seperti mengakses laman-laman jurnal yang akan dijadikan tambahan rujukan hasil penelitian terdahulu. Hal ini menjadi tantangan ekstra bagi tim pendamping agar mereka memiliki kemampuan yang baik dalam menulis artikel ilmiah layak publish di jurnal nasional.

\section{Diskusi}

Terkait kemampuan penulisan karya ilmiah, Para Guru pada dasarnya telah memiliki kapasitas yang baik. Mereka secara berkala telah membuat Penelitian Tindakan Kelas (PTK) sebagai bagian dari proses assessment dari proses belajar mengajar yang mereka lakukan di kelas.

Namun, pada umumnya, mereka kesulitan untuk menulis karya ilmiah yang layak publish di jurnal ilmiah nasional, karena memang secara akademik di lembaga pendidikan SD tidak ada tuntutan keharusan untuk mempublikasikan hasil penelitian tindakan kelas mereka ke dalam jurnal nasional, kecuali untuk digunakan kenaikan kepangkatan pada golongan tertentu.

Melalui pendampingan ini, para Guru SD di Kecamatan Sukun, Kota Malang telah memiliki kemampuan untuk menyusun artikel karya ilmiah sesuai dengan standar jurnal nasional. Pendampingan ini sangat membantu mereka dalam hal kemampuan menulis artikel ilmiah yang menjadi kewajiban dalam pengajuan kenaikan pangkat. ${ }^{9}$ Kemampuan guru dalam menyusun karya ilmiah merupakan salah satu indikator profesionalisme terhadap profesinya sebagai guru, ${ }^{10}$ khususnya guru yang akan mengajukan kenaikan pangkat jabatan golongan IVA untuk meningkat ke golongan IV B dengan membuat karya tulis ilmiah. ${ }^{11}$

\footnotetext{
${ }^{9}$ Reni Reni, Rr Sri Kartikowati, and Nurpit Junus, "Implementasi PERMENPAN Nomor 16 Tahun 2009 Tentang Jabatan Fungsional Guru Dan Angka Kredit (Studi Kasus Pada Kenaikan Pangkat Dan Dampaknya Bagi Guru SDN Di Kecamatan Kandis Kabupaten Siak)," Jurnal Manajemen Pendidikan $\begin{array}{llllll}\text { Penelitian } & \text { Kualitatif } & 2, & \text { no. } & 2 & \text { (n.d.): }\end{array}$ https://jmppk.ejournal.unri.ac.id/index.php/JMPPK/article/viewFile/5329/4999.

${ }^{10}$ Muhsinah Annisa and Hariyati Hamid, "Pengembangan Profesionalisme Guru Melalui Pelatihan Penyusunan Karya Tulis Ilmiah Di Wilayah Pedalaman," Widya laksana 5, no. 2 (2017): 81-84; Moh Hafiyusholeh et al., "Pendampingan Guru Madrasah Untuk Mewujudkan Kompetensi Pedagogik Guru Matematika Yang Berdaya Melalui Penguasaan Soal High Order Thinking Skills (HOTS)," Engagement: Jurnal Pengabdian Kepada Masyarakat 4, no. 1 (2020): 183-200, http://engagement.fkdp.or.id/index.php/engagement/article/view/97.

11 Ibnu Sodiq, Andy Suryadi, and Tsabit Azinar Ahmad, "Program Guru Menulis: Upaya
} 
Hal inilah yang menyebabkan guru menjadi malas untuk mengajukan kenaikan pangkat jabatan dikarenakan minimnya publikasi yang dimiliki guru. Publikasi guru tidak lepas dari kemampuan dan wawasan dalam hal menulis karya ilmiah. ${ }^{12}$ Kendala lain adalah tidak adanya waktu untuk belajar bagi guru dalam mengembangkan profesionalitasnya dalam hal menulis karya ilmiah. Oleh karena itu, maka kegiatan pengabdian kepada masyarakat ini merupakan salah satu solusi agar para Guru SD mampu meminimalisir kendala yang dihadapi oleh mereka dan menjadi guru yang lebih profesional.

\section{Kesimpulan}

Pendampingan penulisan artikel ilmiah bagi para Guru SD di Kecamatan Sukun, Kota Malang menjadi bagian untuk pengembangan kompetensi profesional guru dengan menambah kompetensi untuk menulis artikel ilmiah. Melalui pendampingan dengan pendekatan service learning, tim melakukan pendampingan untuk emmastikan bahwa para Guru SD memiliki kemampuan dalam menulis artikel ilmiah layak publish di Jurnal Ilmiah Nasional. Hasil pendampingan ini mampu memberikan perubahan pada pengetahuan dan ketrampilan bagi para Guru SD di Kecamatan Sukun, Kota Malang dalam menyusun artikel ilmiah mulai dari penyusunan draf naskah artikel ilmiah sampai mampu menyelesaikan dan mempublikasikan pada jurnal nasional sesuai dengan bidang kajian jurnal yang dituju.

Hasil pendampingan ini merekomendasikan kepada pihak Dinas Pendidikan hendaknya mulai mengagendakan beberapa kegiatan pendampingan secara intensif untuk pengembangan profesionalisme guru, khususnya tentang kemampuan dalam penulisan artikel ilmiah, agar para guru tidak ada kendala dalam mengajukan kenaikan pangkat. Kepada Kepala Sekolah hendaknya berperan aktif untuk bekerja sama dengan lembaga perguruan tinggi agar terbangun sinergi yang baik guna mengembangkan program peningkatan kemampuan menulis artikel ilmiah bagi guru.

\section{Pengakuan}

Kegiatan pengabdian kepada masyarakat ini didukung sepenuhnya oleh Hibah Institusi Universitas Islam Malang (HIMA) tahun 2019.

Peningkatan Kompetensi Profesional Guru Sejarah Dalam Penulisan Karya Ilmiah Di Kabupaten Semarang," Rekayasa: Jurnal Penerapan Teknologi dan Pembelajaran 12, no. 1 (2014): 42-47.

12 Annisa and Hamid, "Pengembangan Profesionalisme Guru Melalui Pelatihan Penyusunan Karya Tulis Ilmiah Di Wilayah Pedalaman." 


\section{Daftar Referensi}

Abdul Rasyid Tolangara, and Rohima Wahyu Ningrum. "Pendampingan Komunitas Sekolah Melalui Kegiatan Vertical Garden Untuk Mewujudkan Sekolah Dasar Berbasis Lingkungan Di SDN 34 Kota Ternate Maluku Utara." Engagement: Jurnal Pengabdian Kepada Masyarakat 2, no. 1 (2018): 62-70. http://engagement.fkdp.or.id/index.php/engagement/article/view/24.

Aisyah, Eny Nur, and Putri Mahanani. "Pelatihan Menulisan Artikel Ilmiah Bagi Guru Sekolah Dasar Dan Taman Kanak-Kanak Kecamatan Tajinan Kabupaten Malang." Abdimas Pedagogi:Jurnal Ilmiah Pengabdian kepada Masyarakat 1, no. 1 (2017): 22-26. http://journal2.um.ac.id/index.php/pedagogi/article/view/1947.

Annisa, Muhsinah, and Hariyati Hamid. "Pengembangan Profesionalisme Guru Melalui Pelatihan Penyusunan Karya Tulis Ilmiah Di Wilayah Pedalaman." Widya laksana 5, no. 2 (2017): 81-84.

Depdiknas. "Permendiknas No. 35 Tahun 2010 Tentang Petunjuk Teknis Pelaksanaan Jabatan Fungsional Guru Dan Angka Kreditnya." Jakarta, Indonesia: Departemen Pendidikan Nasional, 2010.

Fathurrohman, Amang, Alfian Adi Saputra, Fauziyah Rahmawati, M Wildan Adnan, and M Rifqi Nur Habibi. "Peningkatan Kapasitas Fotografer Pemula Melalui Sekolah Fotografi Online (SeFO) Tingkat Jawa Timur Untuk Mewujudkan Fotografer Mahir Dengan Handphone Di Masa Pandemik Covid-19." SOEROPATI 2, no. 2 (2020): https://jurnal.yudharta.ac.id/v2/index.php/soeropati/article/view/2064.

Hafiyusholeh, Moh, Ahmad Lubab, Ahmad Hanif Asyhar, Aris Fanani, Yuniar Farida, Dian C. Rini Novitasari, Nurissaidah Ulinnuha, et al. "Pendampingan Guru Madrasah Untuk Mewujudkan Kompetensi Pedagogik Guru Matematika Yang Berdaya Melalui Penguasaan Soal High Order Thinking Skills (HOTS).” Engagement: Jurnal Pengabdian Kepada Masyarakat 4, no. 1 (2020): 183-200. http://engagement.fkdp.or.id/index.php/engagement/article/view/97.

Malang, BPS Kota. “Kecamatan Sukun Dalam Angka 2020.” Kota Malang: BPS Kota Malang, 2020.

Nusanti, Irene. "Strategi Service Learning Sebuah Kajian Untuk Mengembangkan Kegiatan Pembelajaran." Jurnal Pendidikan dan Kebudayaan 20, no. 2 (2014): 251-260. http://up.openjournaltheme.com/jurnaldikbud/ojs-3.1.24/index.php/jpnk/article/view/142.

Olim, Ayi. "Mencari Metode Pendidikan Karakter Untuk PAUD: Belajar Berbasis Layanan (Service Learning)." In Proceedings of the 4th International Conference on Teacher Education 146-161. Bandung, 2010. http://file.upi.edu/Direktori/PROCEEDING/UPIUPSI/2010/Book_1/MENCARI_METODE_PENDIDIKAN_KARAKTER_UNTUK_PAU 


\section{D_BELAJAR_BERBASIS_LAYANAN_\%28SERVICE_LEARNING\%29.pdf.}

Reni, Reni, Rr Sri Kartikowati, and Nurpit Junus. "Implementasi PERMENPAN Nomor 16 Tahun 2009 Tentang Jabatan Fungsional Guru Dan Angka Kredit (Studi Kasus Pada Kenaikan Pangkat Dan Dampaknya Bagi Guru SDN Di Kecamatan Kandis Kabupaten Siak)." Jurnal Manajemen Pendidikan Penelitian Kualitatif 2, no. 2 (n.d.): https://jmppk.ejournal.unri.ac.id/index.php/JMPPK/article/viewFile/5329/499 9.

S.A.P., Rangga Sa'adillah, Tobroni, Ishomuddin, and Khozin. "Dampak Pendekatan Saintifik Terhadap Sikap Spiritual Siswa Dalam Pembelajaran PAI Di SMA Di Sidoarjo." Jurnal Pendidikan Agama Islam (Journal of Islamic Education Studies) 7, no. 2 (2019): 143-165.

Sari, Ifit Novita. "Kepemimpinan Moral-Spiritual Guru Dalam Pembentukan Karakter Peserta Didik (Studi Multikasus Di Sekolah Dasar Plus Al Kautsar, Sekalah Dasar Negeri Kauman I, Dan Sekolah Dasar Katolik Santa Maria II Di Kota Malang)." Universitas Negeri Malang, 2017. http://repository.um.ac.id/64010/.

Sodiq, Ibnu, Andy Suryadi, and Tsabit Azinar Ahmad. "Program Guru Menulis: Upaya Peningkatan Kompetensi Profesional Guru Sejarah Dalam Penulisan Karya Ilmiah Di Kabupaten Semarang." Rekayasa: Jurnal Penerapan Teknologi dan Pembelajaran 12, no. 1 (2014): 42-47.

Supardi, Supardi. "Implementasi PERMENEGPAN No. 16 Tahun 2009 Tetang Jabatan Fungsional Guru Dan Angka Kreditnya Untuk Peningkatan Profesionalisme Guru." In Penilaian Kinerja Untuk Peningkatan Profesionalisme Guru Berkelanjutan, 2012.

Usra, Meirizal, H Hartati, and D Destriani. "Pelatihan Penulisan Artikel Ilmiah Bagi Guru Sekolah Menengah Atas.” Seminar Nasional Pendidikan 2018, 2018.

Wajdi, Muh Barid Nizarudin, M Burhanuddin Ubaidillah, Sri Mulyani, Khoirul Anwar, Lailatul Istiqomah, Fauziyah Rahmawati, Sholihatul Atik Hikmawati, Diah Retno Ningsih, and Hasan Syaiful Rizal. "Pendampingan Redesign Pembelajaran Masa Pandemi Covid-19 Bagi Tenaga Pendidik Di Lembaga Pendidikan Berbasis Pesantren Di Jawa Timur." Engagement: Jurnal Pengabdian Kepada Masyarakat 4, no. 12020$):$ 266-277. http://engagement.fkdp.or.id/index.php/engagement/article/view/193.

Waldner, Leora S, Murray C Widener, and Sue Y McGorry. "E-Service Learning: The Evolution of Service-Learning to Engage a Growing Online Student Population." Journal of Higher Education Outreach and Engagement 16, no. 2 (2012): 123-150. https://files.eric.ed.gov/fulltext/EJ975813.pdf. 